\title{
A Renowned Indian Physicst, an Obituary of Prof. S. K. Joshi
}

\author{
D. K. Aswal* \\ CSIR-National Physical Laboratory, Dr. K.S. Krishnan Marg, New Delhi, India
}

(C) Metrology Society of India 2020

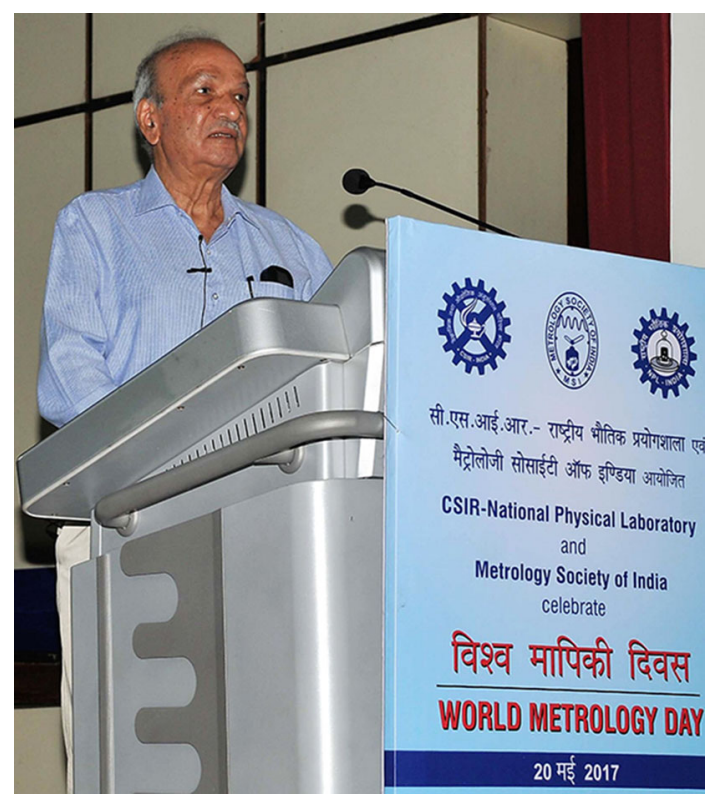

Professor Shri Krishna Joshi

(1935-2020)

Shri Krishna Joshi, popularly known as Professor S. $\mathrm{K}$. Joshi, one of the best science leader and condensed matter physicists of this country left to his heavenly abode on 15 May 2020 at the age of 86 at his residence in Gurugram, Haryana. It was only a few days ago before the corona lockdown started in the country in the month of March, and I visited him and had a long chat with him about his health. At that time, he was suffering from cancer in his thigh and was confined to bed. He had his usual charismatic smile beneath which the deep pain of the illness was evident. In several hours' long discussion, he

*Corresponding author, E-mail: director@nplindia.org narrated his journey from a small village of Uttarakhand to raising the position of Director General of Council for Scientific and Industrial Research, (DG, CSIR), New Delhi. Today May, 16, 2020, the present DG Dr. Sekhar C Mande and myself joined his last journey and remembered his immense contributions to the Indian science and technology. His demise is truly an end of era.

Professor S. K. Joshi was born on June 6, 1935, in a small village of Anarpa in Kumaun, Uttarakhand, India. During his schooling days, he used to walk everyday several kilometers of tough terrains of Himalaya to reach his school. For his higher education, he moved to Allahabad University and obtained BSc and MSc (Physics) degrees, both with first class. In 1957, being the Gold medalist in MSc, he was offered the position of Lecturer in Physics at Allahabad University. In parallel, he started his research work in measurement of diffuse X-ray scattering from organic crystals for his doctoral degree with $\mathrm{K}$. Banerjee and received his $\mathrm{PhD}$ degree in 1962. In 1965, he was offered a position of Visiting Lecturer by University of California, Riverside, USA. After working 2 years in the USA, he returned India and joined as a Professor of Physics, at a pristine age of 32 years, at the University of Roorkee (now IIT Roorkee). His experimental work during his $\mathrm{PhD}$ and his experience in the USA got him seriously interested in theoretical studies of lattice vibrations, i.e., phonons in metals and insulators. In metals, the frequencies of phonons depend on the response of conduction electrons to ion motion, and he proposed a successful phenomenological model incorporating electron response. He was one of the pioneers to understand the lattice dynamics of d-electron metals (e.g., copper and nickel) using a noninteracting $\mathrm{s}$ and $\mathrm{d}$ bands model. He investigated the electronic band structure using Korringa-Kohn-Rostoker method. He used virtual crystal and the coherent potential approximation to calculate the electron states in a number of disordered binary alloys. He was one of the rarest Indian scientists who contributed a Chapter in Solid State Physics, 
published by Academic Press in 1968 on Lattice Dynamics of Metals, and other contributors in this book include Charles Kittle. For his outstanding work, he was awarded with prestigious Shanti Swarup Bhatnagar Award (Physical sciences) in 1972 and by Meghnad Saha Award for Research in Theoretical Sciences in 1974. His group investigated physical properties like electrical conductivity, Hall effect, and surface segregation in disordered binary alloys. His contributions to electron correlations in narrow band ferromagnets using the Hubbard model and its generalizations are highly appreciated. He was elected as a Fellow of Indian Academy of Sciences (IAS), Bangalore, Fellow of Indian National Science Academy (INSA), National Academy of Sciences India (NASI), Third World Academy of Sciences (TWAS), and Russian Academy of Sciences (Foreign Member).

In 1986, he moved from IIT Roorkee to New Delhi to take over the position of the Director of National Physical Laboratory (NPL). It was a coincidence that the discovery of high-temperature superconductors also took place in 1986. His expertise in the lattice vibrations made it easy for him to take the research activities of high-temperature superconductors at NPL. He proposed a new variational method for the periodic Anderson model to study the ground-state behavior of heavy fermions and estimated the $c$-axis resistivity of high-temperature superconductors. NPL also started the work on nanotechnology. He investigated transport of electrons in mesoscopic systems, particularly, the conductance of a single quantum dot and a double quantum dot system. Apart from being an outstanding scientist, he was a visionary leader as well. For visitors coming to NPL, he got a guest house built at NPL campus so that they can work comfortably even beyond the office hours. To attract research scholars to NPL, he got a hostel built for them. For his distinguished contributions in science, Government of India honored him with Padma Shri in 1991.

In 1991, Prof. S. K. Joshi was elevated to the position of Director General of CSIR and Secretary, DSIR, Government of India. It was the time that coincided with beginning of the economic liberalization in India and he successfully steered CSIR for the national scientific and technological needs.

After his superannuation in 1995, his official address became "R. No. 252, Main Building, National Physical Laboratory, Dr. K. S. Krishnan Marg, New Delhi" and remained till his demise. The NPL Research Council chaired by Prof. Arun K. Grover suggested that he should continue as "Scientist of Eminence" at NPL and his vast knowledge should be utilized by the scientists of NPL. He served the nation in various ways. He played a crucial role in establishing new institutes of higher learning, viz. IISER, NISER, New IITs, etc. He guided leading institutions of the country through the Chairmanship of their apex Boards, including IIT Roorkee, Institute of Mathematical Sciences, Chennai, Institute of Physics, Bhubaneswar, Indian Association for Cultivation of Science, Kolkata, Recruitment Assessment Center (RAC DRDO), Recruitment Assessment Board (RAB CSIR), Visvesvaraya National Institute of Technology (VNIT Nagpur), Inter-University Accelerator Centre (IUAC), UGC-DAE, Indore, etc. He served as a member of the Scientific Advisory Committee to Government of India. He also served as Chairman of selection committees to select Directors and Vice Chancellors of many prestigious Institutes and Universities. For his contributions, in 2003, he was honored by Padma Bhushan, the third-highest civilian award in the Republic of India.

In 2015, when I took over the position of Director, NPL, I made a courtesy visit to him. It was a coincidence that he was also just took over as the Chairman of the National Accreditation Board for Testing and Calibration Laboratories (NABL). We had a great discussion on how NPL (the apex body of measurement in the country) and NABL (the apex accreditation body of laboratories in the country) can ensure the quality of Made-in-India products at par with international standards. It was agreed upon that NPL will increase the Calibration and Measurement Capabilities (CMCs) and the International Bureau of Weights and Measures, France, and NABL will try to increase the number of accredited laboratories across the country, which are metrological traceable to SI units of measurements though NPL. In addition, NPL launched several Certified Reference Materials, under the trademark of Bhartiya Nirdeshak Dravyas (BNDs) that provides direct measurement traceability to the laboratories. Many of the BNDs were launched by Prof. Joshi himself. He used to say that NPL should develop all the BNDs so that India becomes self-reliant.

At the end of December 2019, when he started feeling weak, the responsibility of the Chairman, NABL, was entrusted to me. During my last meeting with him, I ensured him that I will carry forward the good work done by him. I was waiting to end the lockdown to tell him that during the period of COVID pandemic, NABL has done a wonderful job by providing the online accreditation to 142 medical testing laboratories across the country for RT-PCR RNA Virus/COVID-19, which has greatly benefited the country in terms of conducting these very important tests. Unfortunately, he left us before I could inform him.

Prof. Joshi immensely contributed to Indian science and academies by serving at various positions including Secretary, Indian National Science Academy (INSA), Foreign Secretary of the Indian National Science Academy (INSA), President of the Indian National Science Academy (INSA), Vice President of the Indian Academy of Sciences, 
President of the National Academy of Sciences President of Indian Physics Association, President of the Materials Research Society of India, President of the Indian Science Congress Association. Prof. Joshi was the brainchild behind enhancing the industry-academia interactions, and bringing the national laboratories to the ambit of deemed universities, e.g., TIFR, HBNI, etc. He was also the Chairman of the elite committee who established 5 DSTCenters Higher Education Institutes, including the Panjab University, Chandigarh. He was awarded a DSc honoris causa from Kumaun University, Kanpur University, Banaras Hindu University, and the University of Burdwan.
His passing is a great loss to the nation. Those of us who have been fortunate enough to know and work with him have lost a great teacher and mentor.

Prof. S. K. Joshi was married to Hema, a gracious and charming lady, who during their 55 years of togetherness supported him in his personal (a strict follower of early to bed and early to rise) as well as professional (follower of simple living and high thinking) life. He leaves behind his wife and a son Sanjay, who is well settled at a high position in the USA with his family.

Publisher's Note Springer Nature remains neutral with regard to jurisdictional claims in published maps and institutional affiliations. 